ORIGINAL ARTICLE

\title{
Agricultural pesticide use and risk of glioma in Nebraska, United States
}

\author{
W J Lee, J S Colt, E F Heineman, R McComb, D D Weisenburger, W Lijinsky, M H Ward
}

Occup Environ Med 2005;62:786-792. doi: 10.1136/oem.2005.020230

Background: To evaluate the risk of the adult glioma associated with farming and agricultural pesticide use, the authors conducted a population based case control study in eastern Nebraska.

Methods: Telephone interviews were conducted with men and women diagnosed with gliomas $(n=251)$ between 1988 and 1993 and controls $(n=498)$ randomly selected from the same geographical area. Unconditional logistic regression was used to calculate adjusted odds ratios (ORs) for farming and for use of individual and chemical classes of insecticides and herbicides, including pesticides classified as nitrosatable (able to form $\mathrm{N}$-nitroso compounds upon reaction with nitrite). Non-farmers were used as the reference category for all analyses.

See end of article for authors' affiliations Results: Among men, ever living or working on a farm and duration of farming were associated with significantly increased risks of glioma ( $\geqslant 55$ years on a farm $\mathrm{OR}=3.9,95 \% \mathrm{Cl} 1.8$ to 8.6 ); however, positive findings were limited to proxy respondents. Among women, there were no positive associations

Correspondence to:

Dr M H Ward, 6120

Executive Blvd EPS 8104,

Occupational and with farming activities among self or proxy respondents. Specific pesticide families and individual pesticides were associated with significantly increased risks among male farmers; however, most of the positive associations were limited to proxy respondents. For two herbicides and three insecticides, use was positively associated with risk among both self and proxy respondents. Based on a small number of Epidemiology Branch, Division of Cancer Epidemiology and Genetics, National Cancer Institute, Rockville, MD, 20852, USA; wardm@ mail.nih.gov

Accepted 3 June 2005 exposed cases, ORs were significantly increased for the herbicides metribuzin $(O R=3.4,95 \% \mathrm{Cl} 1.2$ to 9.7) and paraquat $(\mathrm{OR}=11.1,95 \% \mathrm{Cl} 1.2$ to 101$)$, and for the insecticides bufencarb $(\mathrm{OR}=18.9,95 \% \mathrm{Cl}$ 1.9 to 187$)$, chlorpyrifos $(\mathrm{OR}=22.6,95 \% \mathrm{Cl} 2.7$ to 191$)$, and coumaphos $(\mathrm{OR}=5.9,95 \% \mathrm{Cl} 1.1$ to 32$)$. Conclusion: The authors found significant associations between some specific agricultural pesticide exposures and the risk of glioma among male farmers but not among female farmers in Nebraska; however, most of the positive associations were limited to proxy respondents. These findings warrant further evaluation in prospective cohort studies where issues of recall bias are not a concern.

$\mathrm{T}$ he incidence rate of primary brain tumours was 6.4 per 100000 in the United States in 2000 and has been gradually increasing. ${ }^{1}$ Gliomas represent over $90 \%$ of malignant cancers of the brain and central nervous system. Although brain cancer is one of the most lethal cancers, its aetiology is poorly understood. Exposure to ionising radiation has been consistently associated with increased incidence and other suspected risk factors include certain rare genetic disorders, organic solvents, and electromagnetic fields. ${ }^{2}$

A meta-analysis of 33 studies that evaluated brain cancer and farming found a small but significantly increased risk of brain cancer among farmers. ${ }^{3}$ Six studies were published after the meta-analysis ${ }^{4-9}$ and four ${ }^{5-8}$ found non-significant increased risks of glioma among male farmer workers or farm supervisors. Risk was significantly increased among women in one study ${ }^{5}$ and significantly inverse in another ${ }^{8}$ The increased risk of brain cancer has been hypothesised to be the result of a number of exposures experienced by farmers, including pesticides, fertilisers, solvents, fuels, and zoonotic viruses. ${ }^{10}$ Several studies evaluated risk by type of farming operation or pesticide use. Significantly increased risks were found for livestock farming ${ }^{11}$ including poultry, ${ }^{12}$ dairy, ${ }^{13}{ }^{14}$ and sheep ${ }^{14}$ and with use of pesticides ${ }^{6}{ }^{15}{ }^{16}$ and insecticides ${ }^{17}$ in general. However, the associations with animal farming and pesticide use were not entirely consistent across studies and information on specific pesticides used was not obtained.

Italian farmers ${ }^{17}$ who used insecticides or fungicides had a significant twofold increased risk of brain cancer. The authors hypothesised that exposure to alkyl ureas present in many copper sulfate products used as fungicides in the study area may account for the increased risk of brain cancer

because $\mathrm{N}$-nitroso alkyl ureas and other $\mathrm{N}$-nitroso compounds (NOC) are potent nervous system carcinogens in animals ${ }^{18-20}$ Many pesticides contain amine or amide groups which can react with nitrite to form $\mathrm{N}$-nitrosamines and $\mathrm{N}$-nitrosamides, respectively. ${ }^{21}$ More than 300 pesticide formulations have been surveyed for the presence of nitrosamines or their ability to react with nitrite ${ }^{22-24}$ and NOC contamination has been found in many pesticides commonly used in agriculture. ${ }^{25}$

We conducted a population based case control study in Nebraska to determine if agricultural pesticide exposures were associated with the risk of adult glioma. An additional aim of our study was to evaluate exposure to NOC and NOC precursors and risk of glioma. Here we present results for farming and agricultural pesticide use including use of nitrosatable pesticides.

\section{MATERIALS AND METHODS}

Study population

The current study was part of the Nebraska Health Study II, which was designed to investigate the potential roles of occupational and dietary risk factors in adult glioma, oesophageal adenocarcinoma, and stomach cancer in 66 counties of eastern Nebraska. The study population has been described previously. ${ }^{26}{ }^{27}$ Briefly, all participants were White male or female residents of these 66 counties, aged 21 years or older. Histologically confirmed incident primary adult glioma cases diagnosed between I July 1988 and 30 June

Abbreviations: $\mathrm{Cl}$, confidence interval; GBM, glioblastoma multiforme; NOC, N-nitroso compounds; OR, odds ratio 
1993 were identified from the Nebraska Cancer Registry, or from 11 participating hospitals in Lincoln and Omaha covering more than $94 \%$ of adult glioma cases in the study population.

Controls were randomly selected from the control group of a previous population based case control study of nonHodgkin's lymphoma, Hodgkin's disease, multiple myeloma, and chronic lymphocytic leukaemia conducted in 1986-87 in the same base population. ${ }^{28}$ In the previous study the controls were selected by a 3:1 frequency matching by race, sex, vital status, and 5 year age groups to the overall case distribution. Controls under the age of 65 years were selected from the general population by random digit dialing ${ }^{29}$ and those 65 years and over were identified from Medicare files. Controls for deceased cases were selected from Nebraska mortality records with the additional matching factor of year of death. Controls for the current study were randomly selected from the previous study controls and were frequency matched by age, sex, and vital status to the combined distribution of the glioma, stomach, and oesophageal cancer cases. Because of inadequate numbers of younger controls for the glioma study, 23 additional controls identified by random digit dialing $(n=3)$ or from death certificates $(n=20)$ were interviewed. Self responding controls were oversampled to allow for more study power in subgroup analyses by respondent type.

\section{Interviews}

Glioma cases, controls, or their proxies were interviewed by telephone during 1992-94 using a structured questionnaire containing information about demographics, smoking and alcohol consumption, diet, family history of cancer, complete residential and occupational history, medical history, and other factors. Among those who lived or worked on a farm, we asked a detailed history of pesticide use on the farm as well as years of farming activity and the size of the farm where they lived or worked the longest. Subjects were queried about the use of specific pesticides; the pesticide list was developed with the assistance of local agricultural experts and included 20 insecticides and 17 herbicides used on Nebraska crops over the previous 40 years. All of the questions about pesticide use were for the time period before 1985, the time frame of the previous study.

Of 282 eligible cases, interviews were obtained for 251 (89\%) (139 men, 112 women). Of the eligible interviewed cases, $87 \%$ were astrocytic (56\% of cases were glioblastoma multiforme), $8 \%$ were oligodendrogliomas, $2 \%$ ependymomas, $2 \%$ mixed gliomas, and $1 \%$ other unspecified gliomas. Due to the severity of the disease, interviews were conducted with proxies for $76 \%$ of cases. Most proxy respondents were either spouses $(62 \%)$ or other first degree relatives (33\%).

Of 606 eligible controls, 503 (83\%) were interviewed. The response rate for controls in the original study was $87 \%$, giving an overall control response rate of $75 \%$ for this study. Five controls were excluded after the interview due to a reported diagnosis of a brain tumour, leaving 498 controls in the analysis. Among these controls, $60 \%$ of the interviews were conducted with proxies. Proxy respondents were primarily spouses (45\%) or other first degree relatives (46\%).

\section{Data analysis}

We estimated glioma risk for individual herbicides and insecticides and for chemical family groupings. Additionally, through a review of the literature and the expert judgment of an NOC chemist (W Lijinsky), we grouped the pesticides according to their ability to react with nitrite to form NOCs. We determined the likely carcinogenicity of the NOC derivative through a review of animal studies. ${ }^{30}{ }^{31}$ For nitrosatable pesticides that had not been tested in animals, a judgment was made (by WL) as to their likely carcinogenicity based on the stability of the N-nitroso derivative and the structural similarity to tested compounds. Eleven of the 17 herbicides evaluated were considered nitrosatable $(2,4,5-\mathrm{T}$, 2,4-D as dialkylamine salts, EPTC, glyphosate, trifluralin, atrazine, butylate, cyanazine, dicamba, metolachlor, propachlor), and the derivatives of the first five were judged to be likely animal carcinogens. Five of the 20 insecticides evaluated were considered nitrosatable (bufencarb, carbaryl, carbofuran, famphur, nicotine), and all five nitrosatable insecticides were considered likely animal carcinogens.

We used unconditional logistic regression to calculate odds ratios (ORs) and 95\% confidence intervals (CIs) with Stata software (version 8.0). ${ }^{32}$ All significance tests were two sided $(\alpha=0.05)$. The ORs for farming activity and pesticide use were calculated using non-farmers as a reference group. Subjects who lived or worked on a farm only before age 18 $(n=145)$ were evaluated separately because their farming experience was of short duration and their pesticide use was generally low. Trend tests were performed by assigning scores to categorical variables using the median value among controls and treating the scored variables as continuous variables in the logistic analyses.

Odds ratios were adjusted for age $(\leqslant 49,50-59,60-69$, $\geqslant 70$ ), sex, and respondent type. Separate analyses by sex and respondent type were also conducted. Women reported very little pesticide use, therefore our analyses of individual pesticides was limited to men. We evaluated as possible confounders variables that were associated with risk of glioma in our study population. These included a history of head injury, marital status, education level, alcohol consumption, medical history of diabetes mellitus, dietary intake of $\alpha$ - and $\beta$-carotene, and dietary fibre. None of these factors changed the ORs by more than $10 \%$ and the final models were adjusted only for age, sex, and respondent type.

\section{RESULTS}

The characteristics of brain cancer cases and controls have been described previously. ${ }^{26}$ For both men and women the cases tended to be younger than controls as a result of the frequency matching by age across all case groups which included gastrointestinal cancer cases. Because of the higher matching ratio for self responding cases, there was a higher proportion of self responding controls than cases. A greater proportion of cases completed some education beyond high school and had a family history of brain cancer.

Overall, brain cancer risk was increased among farmers and the association was stronger among men who worked on a farm after age 18 (table 1); however, the increased risk for both groups of farmers was only observed among proxy respondents. Among self respondents, the association with farming was inverse, although it was not statistically significant. We observed a pattern of increasing risk with duration of farming among both self and proxy respondents, although the ORs were much stronger among proxies. Increasing average farm size was not associated with increasing glioma risk. There were no increased risks of glioma among women who lived or worked on a farm before age 18 or as an adult (adult farmers OR $=0.7,95 \%$ CI 0.4 to 1.2), regardless of duration or average farm size (not shown). Among women the ORs for farm work, duration, and farm size were similar for proxy and self respondents (not shown).

Overall, brain cancer risk was increased among adult male farmers reporting that insecticides ( $\mathrm{OR}=1.8$, CI 1.0 to 3.0), herbicides ( $\mathrm{OR}=1.7$, CI 1.0 to 3.0), or nitrosatable pesticides $(\mathrm{OR}=1.9, \mathrm{CI} 1.1$ to 3.4$)$ were used on the farm on which they lived or worked (table 2). Risks of twofold or greater were observed for organophosphate insecticides, dinitroaniline herbicides, and triazine herbicides. The increased risks were 
Table 1 Odds ratios (ORs) and 95\% confidence intervals $(\mathrm{Cls})$ for brain cancer by farming activity among male farmers

\begin{tabular}{|c|c|c|c|c|c|c|c|c|c|c|c|c|c|c|c|}
\hline & \multicolumn{5}{|l|}{ Overall } & \multicolumn{5}{|l|}{ Self } & \multicolumn{5}{|l|}{ Proxy } \\
\hline & \multirow[b]{2}{*}{ Controls } & \multicolumn{3}{|c|}{ Cases } & \multirow{2}{*}{$\begin{array}{l}p \text { for } \\
\text { trend }\end{array}$} & \multirow[b]{2}{*}{ Controls } & \multicolumn{3}{|c|}{ Cases } & \multirow{2}{*}{$\begin{array}{l}\mathrm{p} \text { for } \\
\text { trend }\end{array}$} & \multirow[b]{2}{*}{ Controls } & \multicolumn{3}{|c|}{ Cases } & \multirow{2}{*}{$\begin{array}{l}\mathrm{p} \text { for } \\
\text { trend }\end{array}$} \\
\hline & & $n$ & $\mathrm{OR}^{*}$ & $95 \% \mathrm{Cl}$ & & & $n$ & OR† & $95 \% \mathrm{Cl}$ & & & $n$ & ORt & $95 \% \mathrm{Cl}$ & \\
\hline $\begin{array}{l}\text { Non-farmers } \\
\text { Farmers }\end{array}$ & 112 & 49 & 1.0 & Ref $\neq$ & & 40 & 20 & 1.0 & Ref $\neq$ & & 72 & 29 & 1.0 & Refł & \\
\hline Only before age $18 \S$ & 49 & 27 & 1.3 & $0.7-2.4$ & & 27 & 5 & 0.4 & $0.1-1.2$ & & 22 & 22 & 2.5 & $1.2-5.3$ & \\
\hline $\begin{array}{l}\text { Adult farmers } \\
\text { Adult farmers** }\end{array}$ & 122 & 62 & 1.7 & $1.0-2.9$ & & 35 & 12 & 0.7 & $0.3-1.8$ & & 87 & 50 & 2.6 & $1.4-4.9$ & \\
\hline Years farmed & & & & & & & & & & & & & & & \\
\hline$\leqslant 24$ & 29 & 12 & 1.2 & $0.5-2.7$ & & 9 & 2 & 0.3 & $0.1-1.8$ & & 20 & 10 & 2.1 & $0.8-5.8$ & \\
\hline $25-54$ & 34 & 18 & 1.6 & $0.8-3.3$ & & 11 & 6 & 1.0 & $0.3-3.4$ & & 23 & 12 & 2.2 & $0.9-5.5$ & \\
\hline$\geqslant 55$ & 40 & 24 & 3.9 & $1.8-8.6$ & 0.001 & 9 & 3 & 1.4 & $0.2-7.9$ & 0.885 & 31 & 21 & 6.2 & $2.3-16.2$ & $<0.001$ \\
\hline \multicolumn{16}{|l|}{ Average acres } \\
\hline$<160$ & 38 & 17 & 1.7 & $0.8-3.7$ & & 10 & 3 & 0.8 & $0.2-3.4$ & & 28 & 14 & 2.6 & $1.0-6.4$ & \\
\hline $160-320$ & 31 & 26 & 3.3 & $1.6-6.8$ & & 4 & 2 & 0.9 & $0.2-5.9$ & & 27 & 24 & 4.6 & $2.0-10.6$ & \\
\hline$>320$ & 35 & 14 & 1.3 & $0.6-2.7$ & 0.061 & 19 & 7 & 0.7 & $0.2-2.2$ & 0.588 & 16 & 7 & 1.9 & $0.7-5.8$ & 0.006 \\
\hline
\end{tabular}

*Odds ratio adjusted for age $(\leqslant 49,50-59,60-69, \geqslant 70)$ and respondent type.

†Odds ratio adjusted for age $(\leqslant 49,50-59,60-69, \geqslant 70)$.

$\ddagger$ Reference category: non-farmers.

§Subjects who lived or worked on a farm only before age 18

- Subjects who had lived or worked on a farm as an adult (>18 years).

**Numbers may not sum to total adult farmers due to missing information on years farmed and farm size.

limited to proxy respondents; whereas with the exception of dinitroaniline herbicide class, the associations were inverse among self respondents. Among women, there were no significant associations for any of the pesticide classes, regardless of respondent type (data not shown).

Odds ratios for individual pesticides are presented in table 3 if five or more male cases reported that the pesticide was used. Overall, risk was significantly increased for several herbicides (atrazine, metribuzin, paraquat, pendimethalin, trifluralin) and insecticides (bufencarb, chlorpyrifos, coumaphos, fonofos, terbufos). Among these pesticides with significantly increased risks overall, ORs were increased among both self and proxy respondents for metribuzin, paraquat, bufencarb, chlorpyrifos, and coumaphos. Additionally, non-significant increases of twofold or greater were observed among both self and proxy respondents for the herbicide bentazon and the insecticides benzene hexachloride and disulfoton. We attempted to evaluate trends by number of years and number of days per year these pesticides were used, but there were insufficient numbers of exposed individuals.

Table 4 shows ORs for brain cancer and use of pesticide chemical classes among adult male farmers by histological subtype. Among glioblastoma multiforme (GBM) cases, risk was non-significantly increased twofold for the dinitroaniline, phenoxy, and triazine herbicides. We observed

Table 2 Odds ratios (ORs) and 95\% confidence intervals (Cls) for brain cancer for ever-use of pesticides chemical classes among adult male farmers

\begin{tabular}{|c|c|c|c|c|c|c|c|c|c|c|c|c|}
\hline & \multicolumn{4}{|l|}{ Overall } & \multicolumn{4}{|l|}{ Self } & \multicolumn{4}{|l|}{ Proxy } \\
\hline & \multirow[b]{2}{*}{ Controls } & \multicolumn{3}{|c|}{ Cases } & \multirow[b]{2}{*}{ Controls } & \multicolumn{3}{|c|}{ Cases } & \multirow[b]{2}{*}{ Controls } & \multicolumn{3}{|c|}{ Cases } \\
\hline & & $\mathbf{n}$ & $\mathrm{OR}^{*}$ & $95 \% \mathrm{Cl}$ & & $\mathbf{n}$ & OR† & $95 \% \mathrm{Cl}$ & & $n$ & ORt & $95 \% \mathrm{Cl}$ \\
\hline Non-farmers & 112 & 49 & 1.0 & Ref $\ddagger$ & 40 & 20 & 1.0 & Refł & 72 & 29 & 1.0 & Ref $\ddagger$ \\
\hline Insecticides§ & 77 & 42 & 1.8 & $1.0-3.0$ & 30 & 10 & 0.7 & $0.3-1.7$ & 47 & 32 & 3.0 & $1.5-6.2$ \\
\hline Farmers, no use & 31 & 10 & 1.5 & $0.6-3.6$ & 3 & 2 & 10.1 & $0.6-181.2$ & 28 & 8 & 1.5 & $0.6-4.2$ \\
\hline Carbamate & 36 & 20 & 1.7 & $0.8-3.3$ & 17 & 6 & 0.7 & $0.2-2.2$ & 19 & 14 & 3.0 & $1.2-7.5$ \\
\hline Organochlorine & 47 & 26 & 1.9 & $1.0-3.6$ & 20 & 5 & 0.5 & $0.2-1.8$ & 27 & 21 & 3.6 & $1.6-8.1$ \\
\hline Organophosphorus & 46 & 30 & 2.0 & $1.1-3.7$ & 23 & 7 & 0.6 & $0.2-1.7$ & 23 & 23 & 4.4 & $1.9-10.1$ \\
\hline Herbicides§ & 70 & 38 & 1.7 & $1.0-3.0$ & 28 & 9 & 0.6 & $0.2-1.7$ & 42 & 29 & 2.8 & $1.4-5.9$ \\
\hline Farmers, no use & 41 & 11 & 1.2 & $0.5-2.6$ & 6 & 3 & 1.5 & $0.3-8.0$ & 35 & 8 & 1.2 & $0.5-3.3$ \\
\hline Acetanilide & 34 & 22 & 1.8 & $0.9-3.6$ & 17 & 7 & 0.7 & $0.2-2.1$ & 17 & 15 & 3.3 & $1.3-8.2$ \\
\hline Benzoic acid & 29 & 14 & 1.4 & $0.6-2.9$ & 15 & 4 & 0.5 & $0.1-2.0$ & 14 & 10 & 2.4 & $0.9-6.5$ \\
\hline Carbamate & 22 & 14 & 1.7 & $0.8-3.9$ & 9 & 3 & 0.7 & $0.2-3.1$ & 13 & 11 & 2.9 & $1.1-7.8$ \\
\hline Dinitroaniline & 16 & 17 & 2.9 & $1.3-6.6$ & 8 & 5 & 1.1 & $0.3-3.8$ & 8 & 12 & 5.5 & $1.8-16.4$ \\
\hline Phenoxy & 56 & 32 & 1.8 & $1.0-3.3$ & 24 & 7 & 0.6 & $0.2-1.6$ & 32 & 25 & 3.3 & $1.5-7.2$ \\
\hline Triazine & 42 & 27 & 2.0 & $1.0-3.7$ & 20 & 7 & 0.7 & $0.2-2.0$ & 22 & 20 & 3.7 & $1.6-8.7$ \\
\hline \multicolumn{2}{|c|}{ Nitrosatable pesticides use 61} & 36 & 1.9 & $1.1-3.4$ & 27 & 9 & 0.7 & $0.2-1.8$ & 34 & 27 & 3.4 & $1.6-7.3$ \\
\hline
\end{tabular}

*Odds ratio adjusted for age $(\leqslant 49,50-59,60-69, \geqslant 70)$ and respondent type.

†Odds ratio adjusted for age $(\leqslant 49,50-59,60-69, \geqslant 70)$.

†Reference category: non-farmers.

§Individual pesticides were grouped into herbicides (2,4,5-T, 2,4-D, alachlor, atrazine, bentazon, butylate, chloramben, cyanazine, dicamba, EPTC, glyphosate, metolachlor, metribuzin, paraquat, pendimethalin, propachlor, trifluralin) and insecticides (aldrin, benzene hexachloride, bufencarb, carbaryl, carbofuran,

chlordane, chlorpyrfios, coumaphos, DDT, diazinon, dieldrin, disulfoton, famphur, fonofos, heptachlor, lindane, malathion, nicotine, phorate, terbufos). We also classified the pesticides into their chemical families: acetanilide herbicides (alachor, metolachlor, propachlor), benzoic acid herbicides (chloramben, dicamba), carbamate herbicides (butylate, EPTC), dinitroaniline herbicides (pendimethalin, trifluralin), phenoxy herbicides (2,4,5-T, 2,4-D), triazine herbicides (atrazine, cyanazine, metribuzin), carbamate insecticides (bufencarb, carbaryl, carbofuran), organochlorine insecticides (aldrin, benzene hexachloride, chlordane, DDT, dieldrin, heptachlor, lindane), organophosphorus insecticides (chlorpyrfios, coumaphos, diazinon, disulfoton, famphur, fonofos, malathion, phorate, terbufos). -Nitrosatable pesticides includes 11 herbicides (2,4,5-T, 2,4-D, atrazine, butylate, cyanazine, dicamba, EPTC, glyphosate, metolachlor, propachlor, trifluralin) and five insecticides (bufencarb, carbaryl, carbofuran, famphur, nicotine). 


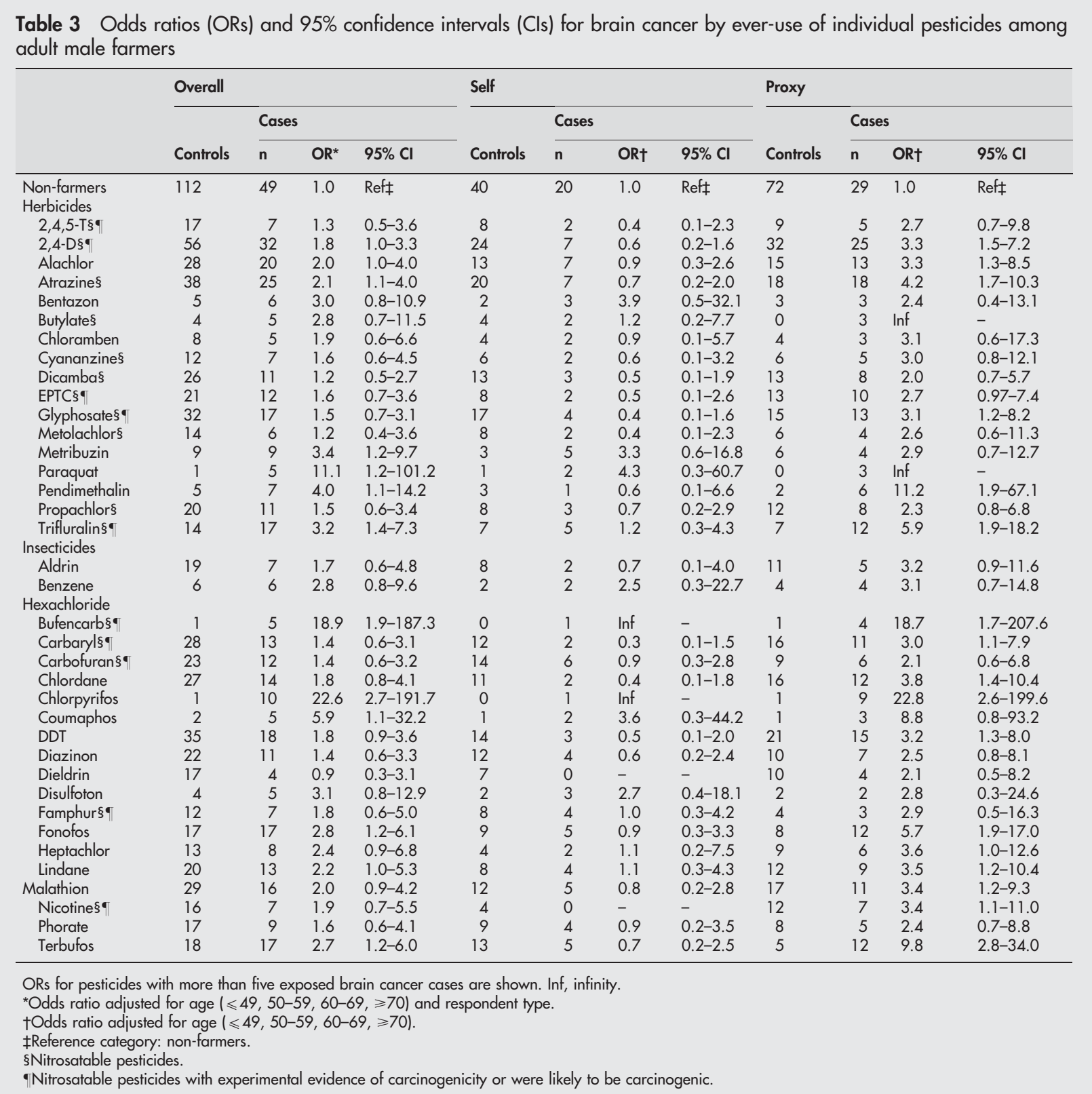

statistically significant positive associations with use of organochlorine insecticides, organophosphorous insecticides, and dinitroaniline herbicides among cases with astrocytoma other than GBM, and non-significantly increased ORs of twofold or greater for carbamate insecticides, and acetanilide, carbamate, and triazine herbicides. Nitrosatable pesticide use was associated with a non-significant twofold increased risk of both GBM and other astrocytomas. As before, the positive associations that we observed were generally limited to proxy respondents (data not shown). The number of cases with other types of glioma was small and we observed no significantly increased risk for any pesticide group. The number of exposed cases was too few to evaluate individual pesticides by histological type.

\section{DISCUSSION}

We found an increased risk of brain cancer among men who lived or worked on a farm and risk increased with duration; farming was not a risk factor among women. Among men, the positive association with ever having lived or worked on a farm was limited to proxy respondents. Risk was also significantly increased among men who used specific pesticides and pesticide chemical classes; however, the positive results were mostly limited to proxy respondents. The exceptions were for two herbicides-metribuzin and paraquat-and for three insecticides-bufencarb, chlorpyrifos, and coumaphos-for which we observed significantly increased risks of glioma overall, and positive associations among both self and proxy respondents based on small numbers of exposed cases. When we analysed pesticide chemical classes, including the nitrosatable pesticides, by histological type, we found a pattern of somewhat stronger risks for astrocytomas other than GBM; however, as we observed for cases overall, risk was largely limited to proxy respondents.

Exposure to nitrosatable pesticides or to pesticides contaminated with nitrosamines has been suggested as a possible explanation for the higher rates of brain cancer among farmers because of the long standing hypothesis that NOC exposure is a potential risk factor for this cancer. ${ }^{18-20} 3334$ Bufencarb, which was associated with an increased risk in both self and proxy respondents, is a nitrosatable carbamate 
Table 4 Odds ratios (ORs) and 95\% confidence intervals (Cls) for brain cancer for ever-use of pesticides classes by histological types among adult male farmers

\begin{tabular}{|c|c|c|c|c|c|c|c|c|c|c|}
\hline & \multicolumn{4}{|c|}{ Glioblastoma multiforme } & \multicolumn{3}{|c|}{ Astrocytoma } & \multicolumn{3}{|c|}{ Other glioma } \\
\hline & \multirow[b]{2}{*}{ Controls } & \multicolumn{3}{|c|}{ Cases } & \multicolumn{3}{|c|}{ Cases } & \multicolumn{3}{|c|}{ Cases } \\
\hline & & $\mathbf{n}$ & $\mathrm{OR}^{*}$ & $95 \% \mathrm{Cl}$ & $\mathbf{n}$ & $\mathrm{OR}^{*}$ & $95 \% \mathrm{Cl}$ & $\mathbf{n}$ & $\mathrm{OR}^{*}$ & $95 \% \mathrm{Cl}$ \\
\hline Non-farmers & 112 & 25 & 1.0 & Reft & 15 & 1.0 & Reft & 9 & 1.0 & Reft \\
\hline Insecticides & 77 & 23 & 2.0 & $1.0-4.1$ & 14 & 1.7 & $0.7-4.0$ & 5 & 1.0 & $0.3-3.3$ \\
\hline Farmers, no use & 31 & 10 & 2.3 & $0.9-6.1$ & 0 & - & - & 0 & - & - \\
\hline Carbamate & 36 & 7 & 1.3 & $0.5-3.4$ & 10 & 2.6 & $1.0-6.6$ & 3 & 1.1 & $0.3-4.7$ \\
\hline Organochlorine & 47 & 12 & 1.7 & $0.7-3.9$ & 11 & 2.8 & $1.1-7.1$ & 3 & 1.2 & $0.3-5.6$ \\
\hline Organophosphorus & 46 & 13 & 1.3 & $0.9-1.9$ & 13 & 2.6 & $1.1-6.3$ & 4 & 1.1 & $0.3-4.1$ \\
\hline Herbicides & 70 & 21 & 1.9 & $0.9-3.8$ & 12 & 1.6 & $0.7-3.9$ & 5 & 1.1 & $0.3-3.7$ \\
\hline Farmers, no use & 41 & 8 & 1.4 & $0.5-3.6$ & 3 & 1.2 & $0.3-5.1$ & 0 & - & - \\
\hline Acetanilide & 34 & 10 & 1.9 & $0.8-4.7$ & 9 & 2.1 & $0.8-5.5$ & 3 & 0.9 & $0.2-3.8$ \\
\hline Benzoic acid & 29 & 6 & 1.2 & $0.4-9.3$ & 5 & 1.6 & $0.5-5.2$ & 3 & 1.4 & $0.3-6.3$ \\
\hline Carbamate & 22 & 5 & 1.2 & $0.4-3.7$ & 6 & 2.6 & $0.8-8.1$ & 3 & 2.2 & $0.5-9.9$ \\
\hline Dinitroaniline & 16 & 5 & 2.1 & $0.6-6.7$ & 8 & 3.9 & $1.3-11.6$ & 4 & 3.0 & $0.7-12.4$ \\
\hline Phenoxy & 56 & 17 & 2.0 & $0.9-4.3$ & 11 & 1.8 & $0.7-4.5$ & 4 & 1.0 & $0.3-3.8$ \\
\hline Triazine & 42 & 13 & 2.0 & $0.9-4.7$ & 10 & 2.2 & $0.9-5.6$ & 4 & 1.3 & $0.3-4.9$ \\
\hline Nitrosatable pesticides use & 61 & 18 & 2.0 & $0.9-4.2$ & 14 & 2.2 & $0.9-5.1$ & 4 & 0.9 & $0.3-3.5$ \\
\hline
\end{tabular}

insecticide for which there is evidence of carcinogenicity of the N-nitroso derivative. However, two other nitrosatable carbamates (carbofuran and carbaryl) did not show consistent elevated risks of glioma among self and proxy respondents.

The assessment of nitrosability of each pesticide was determined by a literature review and an assessment of the chemical structure by an expert chemist (W Lijinsky). However, past NOC contamination of pesticide formulations was variable $e^{25}$ and likely resulted in misclassification of exposure to nitrosatable pesticides. Also, different pesticides vary in their ability to react with nitrite to form $\mathrm{N}$-nitroso compounds and in their carcinogenicity. ${ }^{22-24}$ Animal evidence for $\mathrm{N}$-nitroso compounds as causing central nervous system tumours is strongest for the $\mathrm{N}$-nitroso ureas, which are potent neurocarcinogens. ${ }^{35}$ However, none of the nitrosatable pesticides on our questionnaire was a urea compound, because urea pesticides were not commonly used in our study area.

Humans are exposed to preformed N-nitroso compounds from a variety of sources. ${ }^{21} 30{ }^{36}$ Dietary intakes are estimated to contribute the majority of NOC exposure. ${ }^{36}$ In this study population, dietary nitrate and nitrite, precursors of NOC, were not significantly associated with risk of brain cancer. ${ }^{26}$ It is also important to consider that the routes of exposure are different for nitrosatable pesticides (inhalation and dermal) versus dietary NOC or NOC precursors (ingestion). Relative to other sources of NOC exposure, occupational exposure via agricultural pesticide use may be small and for this reason it may not be significant for the development of brain cancer. However, that does not rule out the possibility of an increased risk among those with higher exposures or among subgroups with susceptible genotypes for activating nitrosamines. ${ }^{37} 38$

The possible aetiological importance of agricultural pesticide exposure in brain cancer risk has been suggested by previous epidemiological studies. Musicco et al ${ }^{17}$ suggested that exposure to alkyl ureas (components of fungicides used extensively in vineyards) may explain the significant positive association between farming and glioma observed in their case control study in Italy. However, this fungicide was not included in this study because of low usage. A death certificate study in France found significantly increased standardised mortality ratios for vineyard farmers in regions with higher pesticide use compared with farmers in areas with low pesticide use. ${ }^{39}$ A record linkage cohort study in Sweden found increased brain cancer incidence among male farmers with pesticide use assessed by a geographic area. ${ }^{16}$ Population based case control studies in Sweden ${ }^{40}$ and the US $^{6}$ found a non-significant increased risk of glioma with occupational pesticide use. A cohort study in China found a significantly increased risk for occupations with pesticide exposure. ${ }^{15} \mathrm{~A}$ cohort of golf course superintendents in the $U^{41}$ and licensed pesticide users in Italy ${ }^{42}$ had significant excess mortality from brain cancer. However, another study in Norway showed no association between brain cancer incidence or mortality and agricultural pesticide use. ${ }^{43}$ One of the largest studies to date found no association between occupational pesticide exposure and glioma risk among men and women. ${ }^{8}$ None of these studies evaluated risk in relation to specific pesticides or chemical classes of pesticides.

Recently, the Agricultural Health Study, a large cohort study of pesticide applicators in Iowa and North Carolina, reported a statistically significant increased risk of brain cancer associated with exposure to chlorpyrifos, ${ }^{44}$ which is supportive of our positive finding. Chlorpyrifos has neurotoxicological effects in the brains of rats $\mathrm{s}^{45}$ and this association warrants further study. Except for alachlor, ${ }^{46}$ which was not associated with brain cancer risk, use of other pesticides by Agricultural Health Study members has not been evaluated in relation to brain cancer risk due to the small number of cases accrued to date.

Besides pesticides, exposure to animals has been evaluated in several studies. Increased brain cancer risk has been observed among farmers raising specific livestock including cattle, poultry, and sheep. ${ }^{611-14} 47$ However, a large international case control study that evaluated this hypothesis ${ }^{4}$ found no overall association between contact with farm animals and glioma risk. Most of the studies did not evaluate specific exposures related to animal farming which include zoonotic viruses, dust, and pesticides. A recent case control study in the US ${ }^{6}$ found increased risk of glioma associated with spending time in animal confinement buildings, as well as for personally applying pesticides to crops and livestock.

Our case control study of glioma is one of the few studies with comprehensive and detailed information on pesticide use among farmers. The major limitation of our study was the large proportion of proxy respondents. Most of the associations we observed were limited to proxy respondents. 
Main messages

- We found positive associations between agricultural pesticide use and the risk of brain cancer, primarily among proxy respondents.

- For metribuzin, paraquat, bufencarb, chlorpyrifos, and coumaphos, we found significant positive associations overall and positive associations among both self and proxy respondents.

Possible explanations include chance, misclassification of exposure by proxy respondents, or a larger risk among deceased farmers who may have had a more aggressive disease. Additionally, deceased controls may be unrepresentative of the general population which may bias associations.

Chance is a possible explanation, but the larger risk among proxy respondents in each pesticide family and for most histological types argues against this. Use of proxy respondents may introduce non-differential misclassification if proxies are less knowledgeable and tend to underreport use. $^{48-50}$ In our study, proxies of cases and controls were more likely to provide "don't know" responses and were less likely to report use of specific pesticides than subjects themselves. However, this would lead to ORs biased towards the null among proxy respondents, which was the opposite of what we observed.

A spurious positive association with farming would be observed among proxy respondents, if farmers are underrepresented among deceased controls compared with the general population. ${ }^{51}$ Although the association with duration of farming was much stronger among proxies, we found a pattern of increased risk among both self and proxy respondents. Moreover, an analysis of stomach and oesophagus cancer cases and pesticide use in this population, which relied on the same controls, ${ }^{52}$ found null or modest inverse associations among self and proxy respondents for specific pesticides and pesticide families, arguing against an unrepresentative control group.

Differential misclassification because of better recall by proxy respondents of cases than controls could explain the positive associations among proxies. We found no evidence of differential misclassification for other information including dietary intakes, ${ }^{26}$ however, recall of pesticide use could be different. We have some evidence that proxies did not overreport pesticide use, because our questionnaire included a "fake" pesticide (called Scope) embedded with actual pesticides used in Nebraska and for which we asked details of use. Proxy respondents for both cases and controls reported no or little use of the "fake" pesticide (cases, $0 \%$; controls, $1.5 \%)$, whereas self responding cases reported more use than self responding controls (cases, 8.3\%; controls, 1.9\%). Therefore, although it is unlikely that overreporting of pesticide use by proxies explains the observed increases in the risk among proxy respondents, we cannot rule out more accurate recall by proxies for cases and underreporting by proxies for controls.

Few women reported pesticide use on farms where they lived or work, so most of our analyses were limited to men. Lower exposures to pesticides and other farming exposures may explain why farming was not associated with an increased risk of glioma among women.

In summary, we found positive associations between agricultural pesticide use and the risk of brain cancer, primarily among proxy respondents. Although we have no clear explanation for the differences we observed between proxy and self respondents, we are concerned that many of
Policy implications

- These findings warrant further evaluation in prospective cohort studies where issues of recall bias are not a concern.

the positive associations may be due to differential misclassification. For two herbicides, metribuzin and paraquat, and for three insecticides, bufencarb, chlorpyrifos, and coumaphos, we found significant positive associations overall and positive associations among both self and proxy respondents. However, our analyses of individual pesticides among self respondents were limited by small numbers, making it difficult to draw clear conclusions. Recent results from the Agricultural Health Study $y^{44}$ support our finding of a positive association between chlorpyrifos exposure and brain cancer risk. The positive associations we observed for chlorpyrifos and the other pesticides warrant further evaluation, particularly in prospective cohort studies where issues of recall bias are not a concern.

\section{ACKNOWLEDGEMENTS}

The authors thanks Robert Saal, Casey Boudreau, and Carol Russell for assistance in study management and coordination of the study; Monica Seeland and other staff of the Nebraska Cancer Registry for providing data; study interviewers and support staff for their diligent work and the many physicians and study participants who cooperated in this study.

\section{Authors' affiliations}

W J Lee, J S Colt, E F Heineman, M H Ward, Occupational and Environmental Epidemiology Branch, Division of Cancer Epidemiology and Genetics, National Cancer Institute, Bethesda, MD, USA

W J Lee, Department of Preventive Medicine, College of Medicine, Korea University, Seoul, Korea

R McComb, D D Weisenburger, University of Nebraska Medical Center, Omaha, NE, USA

Competing interests: none

W Lijinsky died before this paper was published.

\section{REFERENCES}

1 Ries LAG, Eisner MP, Kosary CL, et al. SEER Cancer Statistics Review, 19752001, National Cancer Institute. Bethesda, MD. Available at http:// seer.cancer.gov/csr/1975_2001/(accessed 18 July 2005).

2 Inskip PD, Linet MS, Heineman EF. Etiology of brain tumors in adults. Epidemiol Rev 1995; 17:382-414.

3 Khuder SA, Mutgi AB, Schaub EA. Meta-analyses of brain cancer and farming. Am J Ind Med 1998;34:252-60.

4 Menegoz F, Little J, Colonna $M$, et al. Contacts with animals and humans as risk factors for adult brain tumours. An international case-control study. Eur J Cancer 2002;38:696-704.

5 Zheng T, Cantor KP, Zhang Y, et al. Occupational risk factors for brain cancer: a population-based case-control study in lowa. J Occup Environ Med 2001;43:317-24.

6 De Roos AJ, Stewart PA, Linet MS, et al. Occupation and the risk of adult glioma in the United States. Cancer Causes Control 2003;14:139-50.

7 Navas-Acien A, Pollan M, Gustavsson P, et al. Occupation, exposure to chemicals and risk of gliomas and meningiomas in Sweden. Am J Ind Med 2002;42:214-27.

8 Schlehofer B, Hettinger I, Ryan P, et al. Occupational risk factors for low grade and high grade glioma: results from an international case control study of adult brain tumours. Int J Cancer 2005; 113:116-25.

9 Carozza SE, Wrensch M, Miike R, et al. Occupation and adult gliomas. Am J Epidemiol 2000;152:838-46.

10 Blair A, Zahm SH. Cancer among farmers. Occup Med 1991;6:335-54.

11 Reif JS, Pearce N, Fraser J. Occupational risks for brain cancer: a New Zealand Cancer Registry-based study. J Occup Med 1989;31:863-7.

12 Delzell E, Grufferman S. Mortality among white and nonwhite farmers in North Carolina, 1976-1978. Am J Epidemiol 1985;121:391-402.

13 Mastrangelo G, Marzia V, Paruzzolo P, et al. [Mortality by tumors and other causes in dairy cattle and other agricultural workers in Veneto]. G Ital Med Lav 1995;17:19-21. 
14 Preston-Martin S, Lewis S, Winkelmann R, et al. Descriptive epidemiology of primary cancer of the brain, cranial nerves, and cranial meninges in New Zealand, 1948-88. Cancer Causes Control 1993;4:529-38

15 Heineman EF, Gao YT, Dosemeci M, et al. Occupational risk factors for brain tumors among women in Shanghai, China. J Occup Environ Med 1995;37:288-93.

16 Wiklund K, Dich J. Cancer risks among male farmers in Sweden. Eur J Cancer Prev 1995;4:81-90.

17 Musicco M, Sant M, Molinari S, et al. A case-control study of brain gliomas and occupational exposure to chemical carcinogens: the risk to farmers. Am J Epidemiol 1988;128:778-85

18 Magee PN. The experimental basis for the role of nitroso compounds in human cancer. Cancer Surv 1989:8:207-39.

19 Preston-Martin S, Correa P. Epidemiological evidence for the role of nitroso compounds in human cancer. Cancer Surv 1989;8:459-73.

20 International Agency for Research on Cancer. IARC Monographs on the Evaluation of Carcinogenic Risks to Humans; some N-nitroso compounds. In IARC Monogr Eval Carcinog Risk Chem.Man. Vol 17 Lyon, France: IARC, 1978;1-349).

21 Preussmann R, Eisenbrand G. N-Nitroso Carcinogens in the Environment. In: Charles E Searle, eds. Chemical carcinogens. Washington, DC: American Chemical Society, 1984;829-68).

22 Cohen SZ, Zweig G. Analytical determination of N-nitroso compounds in pesticides by the United States Environmental Protection Agency-a preliminary study. IARC Sci Publ 1978:333-42.

23 Bontoyan WR, Law MW, Wright DP Jr. Nitrosamines in agricultural and home-use pesticides. J Agric Food Chem 1979;27:631-5.

24 Zweig G, Selim S, Hummel R, et al. Analytical survey of N-nitroso contaminants in pesticide products. IARC Sci Publ 1980:555-64.

25 Ross RD, Morrison J, Rounbehler DP, et al. N-nitroso-compound impurities in herbicide formulations. J Agric Food Chem 1977;25:1416-18.

26 Chen $\mathrm{H}$, Ward MH, Tucker $\mathrm{KL}$, et al. Diet and risk of adult glioma in eastern Nebraska, United States. Cancer Causes Control 2002;13:647-55.

27 Heineman EF, Ward MH, McComb RD, et al. Hair dyes and risk of glioma among Nebraska women. Cancer Causes Control. In press.

28 Zahm SH, Weisenburger DD, Babbitt PA, et al. A case-control study of nonHodgkin's lymphoma and the herbicide 2,4- dichlorophenoxyacetic acid $(2,4$ D) in eastern Nebraska. Epidemiology 1990;1:349-56.

29 Hartge P, Brinton LA, Rosenthal JF, et al. Random digit dialing in selecting a population-based control group. Am J Epidemiol 1984; 120:825-33.

30 Lijinsky W. Reaction of drugs with nitrous acid as a source of carcinogenic nitrosamines. Cancer Res 1974;34:255-8.

31 Borzsonyi M, Torok G, Pinter A, et al. Agriculturally-related carcinogenic risk. IARC Sci Publ 1984:465-86.

32 StataCorp. Stata Reference Manual Release 8. Texas: Stata Press, 2003.

33 Eichholzer M, Gutzwiller F. Dietary nitrates, nitrites, and N-nitroso compounds and cancer risk: a review of the epidemiologic evidence. Nutr Rev 1998;56:95-105

34 Baldwin RT, Preston-Martin S. Epidemiology of brain tumors in childhood-a review. Toxicol Appl Pharmacol 2004;199:118-31.
35 Koestner A. Characterization of $\mathrm{N}$-nitrosourea-induced tumors of the nervous system; their prospective value for studies of neurocarcinogenesis and brain tumor therapy. Toxicol Pathol 1990;18:186-92.

36 Tricker AR. N-nitroso compounds and man: sources of exposure, endogenous formation and occurrence in body fluids. Eur J Cancer Prev 1997;6:226-68.

37 Yang CS, Yoo JS, Ishizaki H, et al. Cytochrome P450IIE1: roles in nitrosamine metabolism and mechanisms of regulation. Drug Metab Rev 1990;22:147-59.

38 De Roos AJ, Rothman N, Inskip PD, et al. Genetic polymorphisms in GSTM1, $-\mathrm{Pl},-\mathrm{T} 1$, and CYP2E1 and the risk of adult brain tumors. Cancer Epidemiol Biomarkers Prev 2003;12:14-22

39 Viel JF, Challier B, Pitard A, et al. Brain cancer mortality among French farmers: the vineyard pesticide hypothesis. Arch Environ Health 1998;53:65-70.

40 Rodvall Y, Ahlbom A, Spannare B, et al. Glioma and occupational exposure in Sweden, a case-control study. Occup Environ Med 1996:53:526-37.

41 Kross BC, Burmeister LF, Ogilvie LK, et al. Proportionate mortality study of golf course superintendents. Am J Ind Med 1996;29:501-6.

42 Figa-Talamanca I, Mearelli I, Valente P, et al. Cancer mortality in a cohort of rural licensed pesticide users in the province of Rome. Int J Epidemiol 1993;22:579-83.

43 Kristensen P, Andersen A, Irgens LM, et al. Incidence and risk factors of cancer among men and women in Norwegian agriculture. Scand J Work Environ Health 1996;22:14-26.

44 Lee WJ, Blair A, Hoppin JA, et al. Cancer incidence among pesticide applicators exposed to chlorpyrifos in the Agricultural Health Study. I Natl Cancer Inst 2004;96:1781-9.

45 Slotkin TA. Cholinergic systems in brain development and disruption by neurotoxicants: nicotine, environmental tobacco smoke, organophosphates. Toxicol Appl Pharmacol 2004;198:132-51.

46 Lee WJ, Hoppin JA, Blair A, et al. Cancer incidence among pesticide applicators exposed to alachlor in the Agricultural Health Study. Am J Epidemiol 2004;159:373-80.

47 Lee $\mathrm{E}$, Burnett $\mathrm{CA}$, Lalich $\mathrm{N}$, et al. Proportionate mortality of crop and livestock farmers in the United States, 1984-1993. Am J Ind Med 2002;42:410-20

48 Johnson RA, Mandel JS, Gibson RW, et al. Data on prior pesticide use collected from self- and proxy respondents. Epidemiology 1993;4:157-64.

49 Brown LM, Dosemeci M, Blair A, et al. Comparability of data obtained from farmers and surrogate respondents on use of agricultural pesticides. Am J Epidemiol 1991;134:348-55.

50 Blair A, Kross B, Stewart PA, et al. Comparability of information on pesticides use obtained from farmers and their proxy respondents. J Agric Saf Health 1995; 1:165-76.

51 Gordis L. Should dead cases be matched to dead controls? Am J Epidemiol 1982;115:1-5.

52 Lee WJ, Lijinsky W, Heineman EF, et al. Agricultural pesticide use and adenocarcinomas of the stomach and oesophagus. Occup Environ Med 2004;61:743-9. 